\title{
Strategising from the perspective of global elites
}

\author{
Robert Galavan \\ Professor of Strategic Management \\ National University or Ireland Maynooth
}

"You just don't have some whizz kid off in a room doing complicated stuff and hey presto we're in the circus and out rolls your strategy." (Kevin Toland)

\section{Introduction}

The concept of strategy or strategising is central to many aspects of management practice today. The concept has evolved as a field of study from its early base in business policy formulation, moved through strategic analysis and strategic planning, and on to the more action oriented strategic management that links formulation and implementation. It then swings from an outward facing perspective to a more inward looking one that considers strategic assets, competences, and capabilities as building blocks in a more uncertain world. Learning organisations, core competences, open innovation, and Blue Ocean strategy are among the many frameworks managers have applied to the strategy problem in a rapidly changing world. Strategy is big business and the quest for the next breakthrough goes on.

Rather than get caught up in the chase for the next idea or search for the holy grail of strategy I have taken the opportunity in this chapter to consider important issues in strategy as described by global elite strategists, each from different industries and with different experiences. What they all have in common are successful track records in globally competitive businesses. They all have a focus on making strategy work, because their job depends on it. 
I conducted interviews with 4 executives and what follows is a synthesis of their thinking, framed by my own biases. Where you spot important insights thank the elites, where it falls down blame me.

The four are very different characters and yet what emerged from the conversations was a view of strategy with amazing similarity in concept, all be it different in context and application.

Each of the participants brought a perspective, insight, and personality unique to them. Kevin Toland is Chief Executive and President of Glanbia USA and Global Nutritionals, part of a multi-billion Euro food business headquartered in Ireland (Kevin works and lives in the USA). Prior to joining Glanbia Kevin worked in the drinks industry in Europe and held positions with Coca-Cola bottlers in Russia. Kevin could be described as a rapid fire machine gun, although that might unfairly frame him as somewhat less than precise, which he isn't. Kevin is they type of executive that could run through 25 strategic objectives with you in 25 minutes and instantly know to hone in on the one you were hoping he would gloss over. Kevin knows the second of the participants, Ned Sullivan, quite well. Kevin worked for Ned when Ned was CEO of Glanbia PLC. Ned described Kevin as a "great contrarian" in the strategic debates and as a valuable counter to the "research based process oriented people".

Ned Sullivan is currently Chairman of a food business and a telecommunications company, Eircom, formerly Ireland's national carrier. He has also chaired businesses as diverse as banking and building. He was formerly CEO of Avonmore Waterford, which became Glanbia PLC. Ned also has the distinction of being the man who brought Bailey's Irish Cream to the world (now one of the top global brands. He went on to develop his career in Grand Metropolitan both in Europe and as President of Asia-Pacific operations.

Peter Robbins, is now an independent innovation consultant, and was previously Global Director of Innovation Excellence at GlaxoSmithKline. Peter has a rich history in the pharmaceutical industry, but his later times at GSK focussed on consumer healthcare products. His experience working to help 
teams innovate and strategise in this very complex arena brought wonderful insights. Finally I chatted with Jim O'Hara, Vice President of Intel's global Technology Manufacturing Group and General Manager of Intel's Irish operations. Jim has been with Intel in Ireland since 1991 and oversaw development from its first fabrication plant and on through the billions of dollars in investment that have followed. Jim has high technology manufacturing in his bloodstream and the experience of a player from a world leading highly capital intensive business in the IT sector nicely rounds out the group.

For such diverse characters bringing very different industry and personal perspectives one would expect very diverging views. Indeed there were differences, for example, some talked of the teasing out of strategy and the evolving dialogue where others describe more blunt exchanges. But behind the different manifestations they all talked in some shape or form about the importance of the strategic conversation, the engagement of people in challenge and dialogue, the need for focus and flexibility.

\title{
Simultaneously managing complexity and simplicity
}

\author{
"Beyond the hill of complexity lies simplicity" Ned Sullivan
}

One of the many fascinating insights from the conversations was the ability of each of these global elites to deal with the complexity of strategy, but at the same time not be bound by it. When somebody tells you that a phenomena that is manifestly complex, is actually quite simple, there are two possible explanations. One, they have not grasped the full impact of the situation they face or two, they understand the complexities very well, but realise that if they are to get others to engage they must simplify it (without losing its essence). Elite leaders in these situations have the capacity to absorb complexity and its underlying uncertainty, and from the morass extract simple coherent principles. 
At the product level Ned Sullivan described the almost torturous process of iteration after iteration in developing the Bailey's brand - now one of the world's leading liqueurs - concluding that developing the Bailey's brand was simple "although it didn't seem simple at the time".

"But we eventually realised that it was blindingly simple in a way and we come back to the core of what the brand was or what makes the brand tick, which was that it tastes great to most people."

The detailed work that follows the simple principles are then actually fairly straight forward because while they are complicated, that is take time and detail to work through, they are not all that complex, they have underlying principles that guide the decision making through the other levels. As Ned described it, once the core of the brand had been simplified the job was then to

"... get out of our own way and make the brand available through distribution, make it appealing through advertising, make it contemporary, keep it relevant and stuff like keeping the pricing and packaging right. I wouldn't say it was straight forward, but once we'd kind of got the formula, if you like, it was more just about hard work to implement it".

\section{Clarity and focus with flexibility}

"So where are you off to, where's the hill, how quickly do you want to climb it, and what are you prepared to do to climb it. It's all very ordinary, unsophisticated stuff. All the sophisticated analysis and the scenarios and the evaluation and the thinking to me are really the tools of achieving simple clear answers to those first couple of questions." (Kevin Toland)

Over and over again in the interviews the job of making strategy simple kept coming up. Simple but not simplistic, and not simple in a way that resolves issues beyond thought processes, but simple in a way that allows you to get to the next level of thinking and to keep on thinking. 
"It's not that they're just simpletons wandering around, the complicated stuff is all still in the engine room but, they're able to ask simple, penetrating questions... through that simple insatiable curiosity they're learning and building the management team's capability". (Kevin Toland)

This search for simplicity is in some ways a search for meaning. At the product level a search for the brand DNA as Peter Robbins described it. Similarly Ned Sullivan described the search for "what makes the brand tick" and the hunt for the "truth that emerges about the brand". So do the relatively narrow issues involved in brand translate to the business and corporate levels? One can answer yes and no to this. Certainly the complexity of the corporate strategy has greater breadth and depth but, at the same time, the need to simplify the challenges to a level that can be grasped and communicated does not diminish.

While brand strategy varies along the lines of pricing, customer perceptions, uniqueness, channels, availability and the like, corporate strategy varies along lines of market opportunities, core competencies, and strategic orientation. These higher order variables are collected in what Peter Robbins described as a cathedral built on strategic pillars. The principles are the same though, the simplicity and the focus at one level removes complexity and uncertainty at the next. While it takes time to get to the required level of clarity once it is there people say "That's obvious ... but that's the challenge, it got to be so clear and so compelling" (Ned Sullivan).

Reaching this level of clarity allows people to get on board with the strategy, quicker and with less investment of time and energy. The energy goes towards making things happen, rather than figuring out what it's all about. Equally it allows people to stay on board when difficult times come along. When shocks hit the firm, if the core of the strategy, the nature of the beast in other words, is robust enough, it creates a steadying hand.

"If you're skimming along at high speed and suddenly in the race you come up to Cape Horn or somewhere and you hit a squall, you don't suddenly say, "Oh sugar should we be in a boat? Should 
we be in the sea? Should we be in the race?" All that it really means you hunker down hard and you may go a bit sideways for a while but, your job is to minimise the sort of drift and maximise your momentum forward to your destination anyway." (Kevin Toland)

So while the timing, the tactics of the race, and the route to the end point are all up for discussion, the notion that you are in a particular race to win isn't. At the same time we live in quite a volatile word and moving out further on strategic horizons it becomes more difficult to predict market demands. Even in this context though there are things we can know, in fact Kevin belittles the proposition that "there is no point in thinking where you want to go because who knows what the future holds" as absurd. In one of his business he simplifies it to a question of "will people be eating cheese in 5,10 , or 50 years". Once you have a sense of an answer to that question it is easier to focus on the subsets. How are the supply chains evolving and where should we be deeper or shallower? Are we in the right market segments? Are we selling cheese as a product and should we be selling it as a product plus service - incorporating logistics handling and risk management?

"Once the firm has clarity on what it's trying to achieve, earthquakes creating cracks in the system present both challenges and opportunity. It is our job to understand the pace of these changes, the risks and the opportunities, and where and how we sit in relation to them" (Kevin Toland).

Kevin went on to explain that unlike many business that have spent two years saying how bad the crisis is

"we quietly cracked on, hit our plan and continued with our growth. Because we had clarity, we were able to say here is where we will slow things down, here is where we will hold costs, here is where we will preserve investment, even if a little thinner than intended, and as the storm clears we will come out of it stronger. We will have adapted but kept the key talent and our competitive advantage and we will have accelerated it relative to others." 
Clarity and focus is also about building solid platforms for harnessing opportunities. Jim O'Hara talked briefly about mobile applications and the way they took off in unexpected ways. How, nevertheless, Intel was able to respond with the Centrino technology that was already being developed, not specifically for the applications it was used in but, as a solid core platform from which they believed opportunities would emerge.

Viewed through the eyes of these global leaders, clarity and focus can both reduce uncertainty and at the same time through the pursuit of excellence provide flexibility and opportunity. Setting targets and objectives plays an important part in this so that organisations goals are "clear and transparent" (Peter Robbins). Yet always built into the discussion is the ability to incorporate flexibility with clarity. Perhaps one of the revealing characteristics of the global elite strategists is their unquestioned ability to live, perhaps even thrive on these ambiguities.

"The process is relentless, it's very focussed and it has to be pretty ruthless in terms of squashing deviations from the strategy once it's determined., but at the same time being open to the necessary evolutions of it." (Ned Sullivan)

Peter Robbins, who worked closely with the business within GSK's consumer division talked extensively about the ability to translate higher level objectives into everyday work for the business teams. He noted that "in order to get people to coalesce around a vision, you have to be able to interpret it in a way that relates to their local activity". Strategy is about getting all the little arrows to line up with the intended direction of the big one. Through properly interpreting the big focus in the context of the smaller ones, you allow people to align themselves. This translation goes right through budgeting, functions, and shared services.

"The real task of the strategist is to ensure that all the little domains and fiefdoms are switched on and coming along with the overall group, delivering in a kind of orchestral symphony. Every initiative must be questioned to ensure that it clearly connects to the strategic pillars" (Peter Robbins). 


\section{Creativity and analysis}

The past couple of decades have seen an explosion in business interest in innovation. This interest has been helpful in some ways, it has raised the profile of the challenges that need to be addressed and it has encouraged firms to engage with innovation as an essential process of business - one that needs to be understood and managed. It has however, also created confusion, with creativity and invention being mistakenly touted as somehow equivalent to innovation. They are of course not the same thing. In the business world creativity is an important component, but most business don't suffer from lack of ideas. They suffer from the inability to sort the good ideas from the bad. There is a tongue-in cheek saying in marketing circles that only $10 \%$ of advertising is effective, the problem is trying to figure out which $10 \%$.

Innovating strategically therefore requires a balance, or perhaps a tension between the creativity that generates ideas and the rigorous analysis that informs resource allocation. It is perhaps on this latter dimension that we see the most significant differences across industries, driven to a large extent by the nature of their risk and in particular the initial and sunk capital costs. In an organisation like Intel the development of a new product often precedes the emergence of the market, required extensive $R \& D$, and sinks capital in dedicated plant and equipment.

Perhaps part of the issue I am highlighting here is driven by the risk of a disconnect between those who create ideas and those who must make judgements to commit capital and implement actions. I am reminded of reports of one of the creative guru's, Edward de Bono's, suggestion to the British Foreign Office that they should send Marmite to helps solve the Arab-Israeli conflict. The logic, with some technical merit, is a lack of zinc in the diet (caused by yeast free unleavened bread). Lack of zinc makes men irritable and belligerent. Marmite, which contains zinc, might therefore make them less irritable and peace could break out. The idea is genuinely creative, radical, outside the box and a 
whole host of other clichés. One wonders however if de Bono was in charge of the Foreign Offices limited resources would this suggestion be implemented? Somehow it strikes me that the tension between creativity and analysis is missing here. We have creativity disconnected from the analysis of the situation. Creativity has no consequences, poor resource allocation does. Those working in such roles must endeavour to close the gap.

In our conversation Jim O'Hara emphasised the testing of ideas more than the creation of them. I certainly never got the sense that this was because there was any lack of ideas, but more a value this capital intensive business placed on rigorous analysis and challenge of each and every idea. He talked about a "more action oriented" approach to strategy than planning implies. An approach where executives are "challenged to come up with hypotheses", the hypotheses are built up and knocked down until eventually "some are chosen and become part of the on-going strategy".

The problem with any situation where ideas are challenged is of course the risk that people present only safe ideas. A common line one hears in response to this issue is that firms make it okay for people to fail and so encourage risk taking. What nonsense! It's never okay to fail, it is certainly acceptable to recognise that failure will happen, but that's not the same as making it okay to fail. Years ago as a quality manager I was trained in the concept of acceptable quality levels (AQL's). AQL was a perversion of the word quality. What it in fact meant was that there was a certain amount of faulty product that it was okay to produce. So in the minds of staff, the acceptable quality level became the acceptable junk level. The proponents argued that failure is a fact of life and so we should acknowledge and control it. But making it okay, which is what AQL's did, is not the same as acknowledging it happens. My retort was a bit cruel, but to the effect that if a nurse was about to handle your new born child, what AQL would you set for dropping babies. Unfortunately I am sure that occasionally babies do get dropped, I recognise that, but that's not the same as saying it is okay. So how do global elites deal with such issues? Jim described his approach in Intel where a culture of informed risk taking is developed, a culture that expects and even demands innovation. 
“... we don't expect people just to do what's prescribed, we expect them to go beyond that... They won't get dinged for coming up with an initiative that ultimately fails in itself. They will get dinged if they haven't set up the work, the experiments, and so on correctly." (Jim O'Hara)

In a slightly different vein, perhaps as Ned Sullivan's background is in somewhat less capital intensive businesses or at least businesses without the huge upfront sunk capital costs of Intel, Ned discussed the strategy process noting:

"it's researched based, it's creative, it's creative tension, it's arguments, it's going down blind alleys sometimes and making huge mistakes at times, but recognise them as quickly as you can and back out of them as quickly as you can",

Perhaps in this context we can allow failure to run a little further because it is possible to do some backing out. Not that failure is necessarily more acceptable, but that it's just not as expensive.

What struck me in the conversations was the fluidity with which they moved from creative thinking, through analysis and on to implementation. It certainly appears that these global elites move easily across academic constructs of creative strategy formulation and implementation without much regard for the distinction. These are not separate phases of a process that lead to outcomes, but elements of a cycle that iterates as meaning is unpicked from data that is collected on the journey. Strategy is creativity, strategy is analysis, strategy is implementation; all simultaneously orchestrated. This is not to say that strategy is so tightly defined that there is no room for opportunity or chance. Kevin Toland put it eloquently when he said

"... there may be accidents in strategy it's just that it can't all be accidental".

\section{Evolution and time}

"I think strategy is an agonising birth process that partly mobilises and taps into the wisdom of the organisation as it evolves. It is also partly a more formal process where people get into a room and 
they get some external people who do an analysis and they show them worldwide comparators and all that. So it's a bit of both and you have to have both I think" (Ned Sullivan)

Ned paints an interesting picture here of the formal planning and informal emergent aspects of strategy development. It's not planned or emergent, it's planned and emergent. All of the interviewees, at some point, came around to the strategic conversation. It was described as difficult, challenging, agonising, and time consuming - a process that took place on aeroplanes, in bars, and chatting over coffee. Through iteration after iteration, building on experience as more was learned the process honed the strategy down tighter and tighter.

Once the core of the strategy has been honed the attention shifts. A management team can only focus in depth on a small subset of the business activities at one time. So when one is satisfied they move on to put more effort into other aspects in a cycle that eventually revolves back around to a review of the strategic principles. As progress is achieved some aspects get simpler but at the same time get harder. For example Ned described setting a target in the early '80s for Bailey's to become the biggest liquor brand in the world. "Lo and behold, by about 1990 or 1991 or so we were the biggest liquor brand in the world - the challenge then is, now what?"

It was interesting to hear that while formal strategy planning sessions played a role, there was little belief that strategy emerged from them. These global elites seemed quite comfortable that one can't know all one needs to know at once and that pressing for answers where they are not ready to come will not deliver good strategy. So while annual cycles of strategy and budgeting played a role in all their lives, there was an explicit recognition that you can't say we are going to start "doing strategy in March, and by May we will have a strategy" (Ned Sullivan). Rather strategy was seen as a process of evolution, emergence, and iteration. A process that could take many years. By taking the time to develop the strategy, by revisiting difficult questions, through diligent process and good research the strategy becomes woven into the fabric of the organisation, "to a certain extent by osmosis". The process is punctuated, but not defined by strategic plans and annual budgets.

"I can remember in a number of companies that kind of agonising period you know you haven't got it and yet it's tantalisingly close - you just can't kind of put your finger on it. Then it emerges and you've got it" (Ned Sullivan).

This sense of giving it the time it needs was echoed by Kevin Toland who reminded me of the importance of being patient. "You can always do something you want to do a day late, it's very hard to undo something if you're a day early".

Kevin went on to describe the traditional annual strategy process as a kind of time bound health check. However, he was advocating a more discursive approach than the checkbox healthcare one. An approach where the unresolved questions are unearthed and picked at over time. He said that rather than rush to solutions or get a poor answer because it fits with the processes timeline, we need to come back to the issue in time when we can get the right answer. Jim O'Hara added a twist to this and advocated a process

"where you're always looking for opportunities rather than planning for a particular outcome. I call it like 'Pacmaning' your way into the future. So the big problem about strategic planning is you tend to look at an end point and then you plan to get to that end point and the problem is in doing so you 
miss a whole range of other opportunities that you're not geared up to look for. So strategic action is more appropriate, a regular process of strategic action and a regular process of possibility, discovering and testing those possibilities". (Jim O'Hara)

\section{Getting real engagement}

"These days strategy is much more active, it's much more focused, it's much more real, it's much more...you know people are serious about it and there's always consequences. If you put up a hypothesis and you can't defend it there's implications for your own career so there's a lot more skin in the game these days than there probably was years ago". (Jim O'Hara)

The skin in the game, as Jim describes it, captures the fact that strategy at these elite levels is not an abstract game. It is real time, difficult, uncertain, and most of all it matters. It matters because these elites have a passion to give leadership and it matters because there are consequences for them and their organisations. This should and does lead to vigorous debates - debates with real stakes, real challenges, real uncertainty. But out of the process of debate must emerge action if any strategy is to be implemented. Real debate, comes from real differences of opinion. Opinions that matter to those that own them and yet to be successful everybody must support the outcome. Jim described a process, probably more than a process actually, a cultural value maybe of "disagree and commit". A "value of openness and debate, but of finality and clarity and then strong leadership".

A similar engagement, perhaps not as explicitly framed was expressed by Peter Robbins. Peter described a perceived shift in the approach to strategy. A shift from a more secretive hierarchical orientation to one that sought to be inclusive. A process of greater transparency and of engagement that ensured people engaged with the priorities. "The more contemporary approaches are about including people and it's more about teams".

As Kevin reflected on the growth in Glanbia and the introduction of new managers he described the importance of making time to "get to know" the key managers, noting that it was "important to tell them some of the folksy stuff about how we think, how we developed and the sort of culture and freedom we give people".

This folksy, engaged, debate intensive approach is a far sight from the clinical application of strategy tools from the traditional MBA programme. In the end I think it just came down to level. In the world of global elite strategists the tools are given, analytical capacity is assumed, and excellence in the application is expected. It is only beyond these standards that the global elite find competitive advantage. Kevin put it well when he said

"I went to school in England for a couple of years and you've got to do the 11 plus to get into grammar school. So everyone that's in grammar school has the 11 plus but not everyone is the same.

So if you're hiring someone from a good strategy house they've all got their 11 plus in strategy, funnily enough what makes the better ones stand out for my money is two characteristics, one is an 
insatiable curiosity, insatiable, simple curiosity as opposed to complex curiosity, and the second thing that actually makes the good ones stand out is a bit of humility."

\section{The final analysis}

In the final analysis it appears that strategy for global elites is much less about analysis than we might have thought. Rigour, testing, challenging, analysing, creativity, leadership, commitment, passion, and even humility are all in the global elite strategists make up. The strategy challenge for the global elite is not a race it is a process, it has few right answers but many evolving ones. It is a tension of creativity and feet on the ground grind. It is at the same time planned and emergent. It is perhaps the ability to believe passionately in all of these opposing concepts that sets global elites apart. 